\title{
Immunotolerance induction in a pediatric hemophilic patient in Costa Rica
}

\author{
(Inmunotolerancia en un paciente hemofílico pediátrico en Costa Rica)
}

Adriana Porras-Moreno y Danny Ugalde-Solera

\begin{abstract}
Hemophilia A is an X - linked bleeding disorder. It can be treated with Factor VIII prophylaxis or on demand treatment. Most countries in the world use prophylaxis as it is less expensive than treating patients when they are bleeding. The production of factor VIII inhibitors is the most common and serious complication of the treatment. Immune tolerance induction (ITI) is the only option of treatment when patients develop inhibitors proven to be successful to eradicate this condition, therefore decreasing inhibitors and costs. A case of a successful immune tolerance induction with low doses of factor VIII (FVIII) in a pediatric patient with severe hemophilia A and FVIII inhibitors is presented. Even though inmunotolerance has been practice before in our country, a case like this has never been published.
\end{abstract}

Keywords: hemophilia A, inhibitors, Immunotolerance, ITI, Costa Rica.

\section{Resumen}

La hemofilia A es una enfermedad ligada al cromosoma $\mathrm{X}$ que predispone al sangrado. Se trata con Factor VIII, ya sea profilaxis o a demanda. La mayoría de países en el resto del mundo utilizan profilaxis, lo cual a la larga es más barato que tratar los pacientes cuando están con un sangrado activo. La producción de inhibidores del factor VIII es la complicación más común y seria del tratamiento. La inmunotolerancia (ITI) es la única opción de tratamiento que ha demostrado satisfactoriamente erradicar esta condición en los pacientes que desarrollan inhibidores, disminuyendo de esta manera no solo los inhibidores sino los costos del tratamiento. Se presenta un caso de inducción satisfactoria de inmunotolerancia con bajas dosis de factor VIII (FVIII)

Trabajo realizado en: el Departamento de Hemato-oncología, servicio de hematología del Hospital Nacional de Niños "Dr Carlos Sáenz Herrera".

Abbreviations: ITI, immune tolerance induction; FVIII, factor VIII; rFVIIa, activated recombinant factor VII; aPCC, activated prothrombin complex concentrate.

Conflict of interest: The author reports no conflict of interest.

凶adie.porras@gmail.com

ISSN 0001-6012/2018/60/3/139-141

Acta Médica Costarricense, (C) 2018

Colegio de Médicos y Cirujanos

de Costa Rica en un paciente pediátrico con hemofilia A severa. A pesar de que la inmunotolerancia se ha practicado antes en Costa Rica, un caso de estos nunca antes había sido publicado.

Descriptores: Hemofilia A, inhibidores, inmunotolerancia, ITI, Costa Rica.

Date received: January 12, 2018

Date approved: May 24, 2018

Hemophilia A is a recessive $\mathrm{X}$-linked bleeding disorder caused by decreased levels of coagulation factor VIII. It is responsible for spontaneous and prolonged bleeding, especially in patients with the severe form of the disease where factor VIII levels are less than $1 \% .{ }^{1}$ To stop or prevent bleeding, factor replacement therapy is used, and one of the most significant complications of this treatment is the production of alloantibodies against FVIII which are called inhibitors and have an impact on approximately $20-30 \%$ of patients. ${ }^{1,2}$ In the presence of inhibitors, the infusion of FVIII becomes less effective because the activity of FVIII is neutralized. In order to stop acute bleeding agents that bypass the need for FVIII, such as activated prothrombin complex concentrate (aPCC) or activated recombinant factor VII (rFVIIa) are used. Bypassing agents are more expensive than regular treatment, for example a vial of $500 \mathrm{U}$ of FVIII (regular treatment) costs $\$ 100$, a patient might need 2 vials three times per week. On the other hand, a vial of aPCC (500 U) costs $\$ 800$ and rFVIIa ( $2 \mathrm{mg}$ ) costs $\$ 1000$. A patient might need up to 4 vials of aPCC every 12 hours or $90 \mathrm{ug} / \mathrm{kg}$ of rFVIIa every 2 hours while they are bleeding. ${ }^{1}$ To eliminate such inhibitors immunetolerance induction, knownas ITI, is the only treatment shown to be successful in up to $80 \%$ of cases. ${ }^{3}$ ITI consists of the regular prolonged exposureof the patient to clotting factor concentrate to induce tolerance and to eradicate the inhibitors. ${ }^{1}$

Although several ITI regimens have been proposed, consensus has not been reached on which dose and type of factor concentrate should be used during ITI. According to the international immunetolerance study, there was no difference in the success rates between the high dose (200 IU/Kg/day) and the low dose $(<50 \mathrm{IU} / \mathrm{kg} /$ thrice weekly) regimens of FVIII, in children or adults with high response inhibitors. ${ }^{4,5}$

\section{Case presentation}

A 10-year-old boy with neurofibromatosis type 1 and severe hemophilia A developed FVIII inhibitors at age 3 in 2010. He was previously treated with on demand FVIII therapy at the national hemophilia treatment center, where high response 
inhibitors were documented. He was then transferred to our hospital in 2013 after a bleeding during a dental extraction, due to social problems. In that occasion he required a blood transfusion and high doses of FVIII. Even though our patient was very active he used to bleed no more than 2 or 3 times per year. In our center low response inhibitors were detected in 2014, but it was not until September 2015 when ITI could be started. Inhibitor titer at the initiation of ITI therapy was negative and the level of FVIII was 1.75\%.

A low dose FVIII regimen with $750 \mathrm{IU} /$ day (50 IU/kg) Monday - Wednesday - Friday was initiated on September $3^{\text {rd }}$, 2015. No aPCC or rFVIIa were used as prophylactic treatment during ITI. aPCC was only used in case of acute bleeding. Six months after ITI was initiated, inhibitor titers were $0.8 \mathrm{BU} / \mathrm{mL}$ and they continued to decrease progressively. The recovery test in the $8^{\text {th }}$ month of ITI was in the normal range, showing that the inhibitor became negative (see table 1). ITI was continued until September 2016 when the FVIII inhibitor titer was undetectable. FVIII inhibitor titers evolution before, during, and after ITI therapy are illustrated in Figure 1.

Nowadays our patient is on FVIII prophylaxis, and he is event free (no bleeding).

\section{Discussion}

Prophylactic replacement therapy is the gold standard ofcare in patients with severe hemophilia, it not only prevents hemorrhage but also its related arthropathy. 5,6 The development of FVIII inhibitors in patients with hemophilia $\mathrm{A}$ is a very difficult and expensive complication of their treatment, ${ }^{2,4,7}$ Even though the presence of an inhibitor does not modify the frequency or severity of the hemorrhage, it could increase morbidity and mortality and make their management even more challenging. ${ }^{3}$

Once an inhibitor develops, regular prophylaxis with FVIII needs to be discontinued and only by-passing agents can be used, which rise both on demand and prophylaxis costs and also represent a less effective haemostatic therapy. ${ }^{2,8}$ ITI is the best way to eradicate the inhibitors permanently, to restore prophylactic FVIII therapy, to stop bleedings and thus to improve the patient's quality of life. ${ }^{2,7,8}$

Several good prognostic factors for ITI have been described, as: 1) FVIII inhibitor titer at the beginning of therapy less than 10 $\mathrm{BU} / \mathrm{ml}$; 2) historical peak inhibitor titer less than $200 \mathrm{BU} / \mathrm{ml}$; 3) peak inhibitor titer during ITI less than $250 \mathrm{BU} / \mathrm{ml}$; 4)

\section{Table 1: FVIII recovery test}

\begin{tabular}{|cccc|}
\hline \multicolumn{3}{c|}{ Table 1: FVIII recovery test } \\
\hline & & \multicolumn{3}{c|}{ Factor VIII Activity } \\
Date & Pretest & 6h later & 24 hours later \\
\hline $19 / 05 / 2016$ & $<1 \%$ & $47 \%$ & $19 \%$ \\
$21 / 06 / 2017$ & $<1 \%$ & $35 \%$ & $8 \%$ \\
\hline
\end{tabular}

Initiation of ITI within 5 years of FVIII inhibitor appearance. The success of ITI is also considered better in younger patients with early ITI. ${ }^{2,3,5}$

Our patient almost met all of the criteria of good prognostic FVIII inhibitor titer at the beginning of ITI was undetectable even though we do not know the titers in the other center. According to our data, $3.9 \mathrm{BU} / \mathrm{mL}$ was the highest titer before ITI, during ITI the highest titer was far less than $250 \mathrm{BU} / \mathrm{mL}$ and ITI was started five years after FVIII inhibitors were detected.

It is known that less bleeding has been reported in patients using a high dose regimen and FVIII tolerance has been achieved faster as well. ${ }^{3}$ However, a high dose FVIII regimen is very difficult to afford for a country like ours, and we cannot expect that a patient pays for his own treatment either, so our patient underwent ITI with a low dose FVIII regimen. A month after ITI was initiated, inhibitor titer was $8.7 \mathrm{BU} / \mathrm{ml}$; the highest titer ever registered in our center showing a normal anamnestic response which is considered to be a common immunological reaction associated with ITI. There are regimens using ITI therapy with high dose FVIII combined with intravenous immunoglobulin. For this regimen a positive elimination of the anamnestic response (less exaggerated) has been described. ${ }^{5}$

ITI should always be continued for at least 9 months and no more than 33-36 months according to different authors. ${ }^{2,3,7}$ In our patient the recovery of FVIII in plasma was normalized within eight months after the initiation of ITI; nevertheless, therapy was continued until September 2016 in order to complete a full year of therapy and by that time FVIII inhibitors were measured again, turning back negative.

ITI complete success is achieved when a negative inhibitor test $(<0.6 \mathrm{BU} / \mathrm{ml})$, FVIII recovery is $>66 \%$, half life $\geq 6$ hours measured after a $72 \mathrm{~h}$ treatment free washout period and no anamnestic reaction for the next FVIII application is observed. A partial response is achieved with a negative inhibitor test and FVIII recovery $<66 \%$ or half life $\leq 6 \mathrm{~h}$ enabling FVIII use over a period of 6 months of on demand treatment or 12 months of prophylaxis after ITI termination. Failure to fulfill the criteria for full or partial response within at least 36 months of ITI

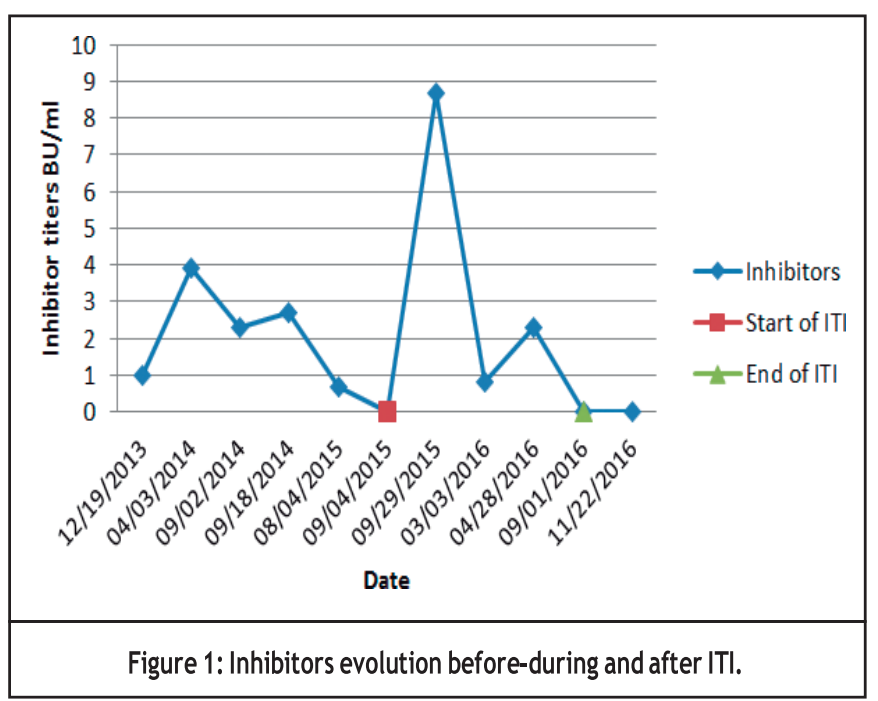




\section{Pediatric immunotolerance induction / Porras-Moreno y Ugalde-Solera}

treatment is considered treatment failure. ${ }^{2,3,7}$ Our patient met criteria for a partial response; he had a negative inhibitor titer with a FVIII recovery test less than $66 \%$.

In a developing country, on demand treatment is more likely to be given: it is enough to stop acute bleeding but poorly prevents arthropathy. A primary prophylaxis regimen early in life should be the number one treatment option for hemophilic patients, and ITI without delay should always be considered once inhibitors were developed. Even though it is an expensive therapy, its cost is compensated by the chronic expensive care a patient with FVIII inhibitors would represent. ${ }^{5,7,9}$

In a country like Costa Rica, with limited economical resources, this patient represents a complete success, and he demonstrates that patients with good prognostic factors might be effectively treated with low-dose FVIII regimen.

\section{References}

1. Maissaa J, Steven P. What is the role of an extended half life product in immune tolerance induction in a patient with severe hemophilia A and high - titer inhibitors?. Hematology Am Soc Hematol Educ Program. 2016; 648-649.
2. Angelika B, Denisa J, Anna M, Eva B, Tatiana P, Julia H, Et al. Inhibitors in Severe Hemophilia A: 25 year Experience in Slovakia. SeminThromb Hemost 2016;42:550-62

3. Ay Y, Ersin T, Yesim 0, Hilkay KT, Dilek I, Gulcihan 0, Ahmet K. Successful immune tolerance induction with low-dose coagulation factor VIII in a patient with hemophilia A from a developing country. Blood coagul fibrinolysis 2015; 27: 729-731

4. K. Holstein, A. Batorova, M. Carvalho, K. Fijnvandraat, P. Holme, K.Kavakli, et al. Current View and outcome of ITI therapy - A change over time? Thromb Res 2016; 148: 38-44.

5. Mizoguchi Y, Furue A, Kagawa R, Chijimatsu I, Tomioka K, Shimomura M. Early eradication of factor VIII inhibitor in patients with congenital hemophilia A by immune tolerance induction with a high dose of immunoglobulin. Int J Hematol 2016;103:473-7

6. Lynn M. Extended half life factor VIII for immune tolerance induction in haemophilia. Haemophilia. 2016; 22:e552-e554.

7. A. Rocino, P.A Cortesi, L.Scalone, L.G. Mantovani, R.Creas, and A. Gringer. Immune tolerance induction in patients with haemophilia A and inhibitors: effectiveness and cost analysus in an European Cohort (the ITER Study). Haemophilia. 2016; 22:96-102.

8. K. Berger, D. Schopohl, D. Eheberg, G.Auerwald, K. Kurnik, and W.Schramm. Treatment of children with Severe Haemophilia A and Inhibitors: a health Economic Evaluation for Germany. Klin Padiatr. 2013;225:152-158

9. N. Ewing, C.Escuriola and W.Kreuz. Prophylaxis with FEIBA in paediatric patients with haemophilia A and inhibitors. Haemophilia. 2015; 21: 358-364 